\title{
Kinetic model for quartz and spinel dissolution during melting of high-level-waste glass batch
}

Richard Pokorny ${ }^{[1]}$, Jarrett A. Rice ${ }^{[2]}$, Jarrod V. Crum ${ }^{[2]}$, Michael J. Schweiger ${ }^{[2]}$, Pavel Hrma ${ }^{[2,3]^{*}}$

[1] Department of Chemical Engineering, Institute of Chemical Technology in Prague. Technicka 5, 166 28 Prague 6, Czech Republic

[2] Pacific Northwest National Laboratory, Richland WA 99352 USA

[3] Division of Advanced Nuclear Engineering, Pohang University of Science and Technology, Pohang, Republic of Korea

* Corresponding author: pavel.hrma@pnnl.gov.

\begin{abstract}
The dissolution of quartz particles and the growth and dissolution of crystalline phases during the conversion of batch to glass potentially affects both the glass melting process and product quality. Crystals of spinel exiting the cold cap to molten glass below can be troublesome during the vitrification of iron-containing high-level wastes. To estimate the distribution of quartz and spinel fractions within the cold cap, we used kinetic models that relate fractions of these phases to temperature and heating rate. Fitting the model equations to data showed that the heating rate, apart from affecting quartz and spinel behavior directly, also affects them indirectly via concurrent processes, such as the formation and motion of bubbles. Because of these indirect effects, it was necessary to allow one kinetic parameter (the pre-exponential factor) to vary with the heating rate. The resulting kinetic equations are sufficiently simple for the detailed modeling of batch-to-glass conversion as it occurs in glass melters. The estimated fractions and sizes of quartz and spinel particles as they leave the cold cap, determined in this study, will provide the source terms needed for modeling the behavior of these solid particles within the flow of molten glass in the melter.
\end{abstract}

\section{Keywords}

Batch melting, Cold cap, Quartz, Spinel, Waste glass

\section{Introduction}

The presence of solid particles in glass is an issue of concern for commercial glass makers [1] as well as for high-level waste (HLW) vitrification [2, 3, 4, 5, 6]. Solid particles, also called stones, 
whether incompletely dissolved raw materials or precipitated crystals, are unacceptable in commercial glass products. In HLW glasses, solid particles become an issue only when they present a processing problem or when they compromise glass durability $[7,8,9,10]$.

Various kinds of solid particles are problematic, such as incompletely dissolved quartz grains [11, 12], crystals of spinels [13], or crystals of nepheline [9]. In this study, we confine our attention to particles that enter molten glass from the cold cap, a layer of reacting glass batch floating on the surface of melt. This restriction rules out nepheline, which is deleterious for glass durability, but forms predominantly during the cooling of HLW glass in canisters [14]. Fig. 1 is a scanning electron micrograph of a HLW glass just below the cold cap. It shows the dissolving quartz residues (dark gray) surrounded with silica-enriched melt (light gray), and spinel crystals (white) distributed in borosilicate (predominantly borate) melt.

The occurrence of residual quartz particles ceased to be a problem for commercial glass makers since highly efficient furnaces have been in operation. But it can be an issue for HLW glasses when rapid melting is combined with short residence times in the melter. Poorly dissolved and incompletely homogenized silica can have a detrimental impact on HLW glass durability because the low-silica matrix glass has a decreased resistance to corrosion by water. An overview summarizing the literature concerned with the dissolution of quartz particles during the conversion of batch to molten glass can be found in reference [2], which reviews studies from the early $20^{\text {th }}$. century up to the first decade of the $21^{\text {st }}$ century. Perhaps the main aspect of quartz as a raw material is the existence of an optimum particle size for achieving the highest melting rate [11]. Smaller quartz particles increase foaming because they dissolve too early and increase melt viscosity at temperatures at which batch gases are still evolving. Larger quartz particles aggregate to clusters, being pushed by ascending bubbles, and resist homogenization. In this study, we are concerned mainly with the dissolution of optimum-sized quartz particles within the cold cap, where the extent of silica incorporation into the glass-forming melt influences viscosity, the rate of batch reactions, and foaming. Also, we intend to determine the fraction and size of quartz particle residues that leave the cold cap and enter into the melt convection currents. 
Spinel crystals do not negatively influence HLW glass durability. The presence of spinel affects the HLW melter processing via settling, particularly in the melter discharge riser during idling periods [8]. Fortunately, spinel settling can be avoided if the crystals are small enough to leave the melter while suspended in glass $[8,13,15]$. The growth and dissolution of spinel crystals in molten glass has been addressed in several papers. Alton et al. [3] showed that the Hixson-Crowell equation better describes spinel growth and dissolution in a HLW glass melter than the Kolmogorov-Johnson-MehlAvrami equation. Izak et al. [16] presented experimental observations of spinel response to the melt temperature history and the addition of noble metals that are effective nucleation agents.

Spinel, usually a solid solution of magnetite, trevorite, nichromite and various other forms [17, 18], grows and then begins to dissolve in the cold cap from which it enters molten glass $[15,16]$. The initial fraction and size of spinel crystals entering convection currents within the melt from the cold cap has a decisive impact on the fate of the crystals inside the melter. However, little attention has been given to this "initial" crystal size, not to mention the effect of the time-temperature history of the batch during its conversion to glass. Even detailed mathematical models of spinel growth, dissolution, distribution, and settling in the waste glass melter [7, 19, 20, 21] simply assumed that spinel particles leave the cold cap at a certain size without justifying it by computation or observation.

Our goal is thus to develop simple kinetic models for the dissolution of quartz and the growth and dissolution of spinel inside the cold cap. These simple models will allow us to estimate the distribution of quartz and spinel fractions within the cold cap as functions of the heating rate that the batch is experiencing, and the solid fractions that exit into the molten glass circulating under the cold cap.

A preliminary version of a cold cap model has recently been developed [22] that solves the heat and mass transfer equations to obtain temperature and velocity profiles in the cold cap with the ultimate goal—after the cold cap model becomes incorporated into the overall melter model—to explore the effects of batch makeup variables and melter conditions on the rate of melting. Together with the waste loading, the rate of melting determines the efficiency of the vitrification technology, including the cleanup life cycle at Hanford [23, 24]. Kinetic equations of batch melting reactions [25, 26] have recently been developed for use in the advanced version of the cold cap model. Our goal in 
this study is to add to the cold-cap model kinetics equations for quartz as the main glass former and spinel as an intermediate crystalline phase of iron-containing HLW glasses.

For the sake of maximum simplicity, while representing the real behavior as closely as possible, we use the $n^{\text {th }}$-order kinetic model for simulation of quartz dissolution. This model was proven adequate for batch melting reactions $[25,26]$ that are complete within relatively narrow intervals of temperature, allowing us to disregard the effects of their mutual interactions and use the standard $n^{\text {th }}$ order kinetic model with constant coefficients; however, the reaction weights were functions of the heating rate. Such a simplification appears inadequate for the kinetics of quartz dissolution and spinel formation, which extend over several hundred Kelvins [2, 12, 16]; thus kinetic coefficients can be functions of the temperature history. We have been able to accommodate this complexity by allowing pre-exponential factors to vary with the rate of heating while keeping activation energies constant.

\section{Theory}

Previous studies $[2,12]$ show that the initial interactions of quartz with batch components via chemical reactions consume very little crystalline material. Most of the quartz mass in the cold cap is dissolved via diffusion [2, 12]. For diffusion-controlled dissolution, the silica mass flux, $j$, at the grainmelt interface can be expressed as $j=\rho_{G} h\left(x_{S G}-x_{S B}\right)$, where $\rho_{G}$ is the melt density, $x_{S G}$ and $x_{S B}$ are the silica mass fractions in melt at the interface and in bulk melt, respectively, and $h$ is the mass transfer coefficient. As discussed in [12], the mass transfer coefficient depends on numerous factors, such as the presence and motion of bubbles, the extent of overlap of concentration boundary layers, etc. A simple, yet sufficient and adequate, model for quartz dissolution kinetics is needed for the cold cap model, a key part of the model of the glass melter. Therefore, we did not attempt to assess the effects of various factors such as nonuniform spatial distribution of quartz particles, their irregular shapes, or the particle-size distribution on the dissolution kinetics. Instead, we attempted to represent the quartz dissolution rate by the $n^{\text {th }}$-order kinetic model: 


$$
\frac{\mathrm{d} x}{\mathrm{~d} t}=A(1-x)^{n} \exp \left(-\frac{B}{T}\right)
$$

where $x$ is the fraction of undissolved quartz, $t$ is the time, $T$ is the temperature, $A$ is the preexponential factor, $n$ is the (apparent) reaction order, and $B=E / R$; $E$ is the activation energy, and $R$ is the universal gas constant.

Spinel formation, growth and dissolution in the cold cap must be modeled differently from quartz dissolution. Based on the past studies as well as present data (see Section 4), crystalline spinel is predominantly formed from hematite. As soon as spinel exceeds the equilibrium fraction, it begins to dissolve in the glass-forming melt. In a stirred mixture where convective diffusion controls the mass transfer rate, the dissolution of spinel can be described by the Hixson-Crowell equation [27]

$$
\frac{\mathrm{d} c_{s}}{\mathrm{~d} t}=2 k_{H}\left(c_{s 0}-c_{s}\right)
$$

where $c_{s}$ is the spinel fraction, $c_{s 0}$ is the equilibrium spinel fraction, and $k_{H}$ is the Hixson-Crowell rate constant. The rate constant follows the Arrhenius law, $k_{H}=k_{H 0} \exp \left(-B_{H} / T\right)$, where $k_{H}$ is the preexponential factor, and $B_{H}=E_{H} / R$ is the reduced activation energy. The Hixson-Crowell equation appeared applicable to spinel growth/dissolution in molten glass [4], where the gravity-driven motion of spinel crystals keeps the diffusion boundary layers around the crystals at a constant thickness [28]. Repressed boundary layers around spinel crystals can be assumed within the cold cap, where motion of gas bubbles is stirring the melt [11].

As discussed in [29, 30], the experimental data on the spinel equilibrium fraction can be represented with reasonable accuracy by the ideal-solution equation for a binary mixture

$$
c_{s 0}=c_{\max }\left\{1-\exp \left[-B_{L}\left(\frac{1}{T}-\frac{1}{T_{L}}\right)\right]\right\}
$$


where $c_{\max }$ and $B_{L}$ are temperature-independent coefficients and $T_{L}$ is the liquidus temperature. As discussed in [3], $c_{\max }$ can be interpreted as the hypothetical total (crystalline plus dissolved) spinel in glass. Eq. (3) for $C_{\mathrm{s} 0}(T)$ is valid only for compositionally uniform HLW glasses. For the cold cap, it can be used when the glass phase is almost fully developed, i.e., in the high-temperature range.

\section{Experimental}

The high-alumina HLW melter feed we used for experiments is a simplified version of a batch designed for the Hanford Waste Treatment and Immobilization Plant [11] (Table 1). This simplified version was formulated to produce a glass of the following composition (with mass fractions in parentheses): $\mathrm{SiO}_{2}$ (0.305), $\mathrm{Al}_{2} \mathrm{O}_{3}(0.240), \mathrm{B}_{2} \mathrm{O}_{3}$ (0.152), $\mathrm{Na}_{2} \mathrm{O}$ (0.096), $\mathrm{CaO}$ (0.061), $\mathrm{Fe}_{2} \mathrm{O}_{3}(0.059)$, $\mathrm{Li}_{2} \mathrm{O}$ (0.036), $\mathrm{Bi}_{2} \mathrm{O}_{3}$ (0.011), $\mathrm{P}_{2} \mathrm{O}_{5}$ (0.011), $\mathrm{F}$ (0.007), $\mathrm{Cr}_{2} \mathrm{O}_{3}$ (0.005), $\mathrm{PbO}$ (0.004), $\mathrm{NiO}(0.004), \mathrm{ZrO}_{2}$ (0.004), $\mathrm{SO}_{3}(0.002), \mathrm{K}_{2} \mathrm{O}$ (0.001), $\mathrm{MgO}$ (0.001), and $\mathrm{ZnO}(0.001)$. The simulated batch was prepared, as described by Schweiger et al. [11], as slurry that was dried at $105^{\circ} \mathrm{C}$ overnight in an oven. The properties of this batch have been well, although not completely, characterized [11, 31, 32, 33, 34] and were used for the initial mathematical modeling of the cold cap [22].

Batch samples were ramp heated at two heating rates, $5 \mathrm{~K} \mathrm{~min}^{-1}$ and $15 \mathrm{~K} \mathrm{~min}^{-1}$. To obtain the amount of crystalline phases during melting, the heating was stopped in successive experiments at temperatures ranging from $100^{\circ} \mathrm{C}$ to $1200^{\circ} \mathrm{C}$ in $100^{\circ} \mathrm{C}$ intervals. Samples were heated in porcelain crucibles for heat treatments up to $500^{\circ} \mathrm{C}$ and in Pt-Rh crucibles for heat treatments above $500^{\circ} \mathrm{C}$.

To measure equilibrium spinel fractions, four glass samples were isothermally heated for 24 hours in Pt crucibles at $950^{\circ} \mathrm{C}, 1050^{\circ} \mathrm{C}, 1150^{\circ} \mathrm{C}$, and $1250^{\circ} \mathrm{C}$. Samples were powdered for X-ray diffraction (XRD) analysis; $\mathrm{CaF}_{2}$ (Fisher Chemicals Lot\# 035567) was added as an internal standard. XRD scans were analyzed for the content of crystalline phases by the Bruker (Madison, WI, USA) programs EVA-14.0.0.0 ${ }^{\circ}$ and TOPAS $4.2^{\odot}$.

\section{Results}

\subsection{Quartz dissolution}


Fig. 2 displays the undissolved fraction of quartz as a function of temperature. As expected, the fraction of undissolved quartz shifted to a higher temperature at the higher heating rate, because the particles had less time to dissolve. The dashed lines in Fig. 2 represent a hyperbolic tangent function fitted to the measured data at temperatures $>700^{\circ} \mathrm{C}$, the region of interest in our study. This auxiliary function was used to estimate the $\mathrm{d} x / \mathrm{d} t$ needed in Eq. (1) for computing the kinetic parameters $A, n$, and $B$. Table 2 lists the results obtained with separate fittings for heating rates 5 and $15 \mathrm{~K} \cdot \mathrm{min}^{-1}$. The solid lines in Fig. 2, which represent the $n^{\text {th }}$-order kinetic model, demonstrate that the model fits measured data adequately.

The apparent reaction order and activation energy are reasonably close to their averages, $n^{\text {ave }}=$ $1.36 \pm 0.04$ and $B^{\text {ave }}=(9.46 \pm 0.99) \times 10^{3}$ K. However, $A$ changes substantially with the heating rate, being nearly eight times as high for $15 \mathrm{~K} \cdot \mathrm{min}^{-1}$ than for $5 \mathrm{~K} \cdot \mathrm{min}^{-1}$. After refitting Eq. (1) with the averages of $n$ and $B$ for the two heating rates, the $A$ values are $A=4.63 \mathrm{~s}^{-1}$ and $9.39 \mathrm{~s}^{-1}$ for $5 \mathrm{~K} \cdot \mathrm{min}^{-1}$ and $15 \mathrm{~K} \cdot \mathrm{min}^{-1}$, respectively; their difference decreased, but remains significant. Hence, while a part of the original difference seen in Table 2 is attributable to the compensation effect between $A$ and $B$ values, $A$ is clearly a function of the heating rate, which should not be surprising. Quartz dissolution proceeds in melter feed parallel with the generation of glass-forming melt and with the formation and growth of bubbles. With less silica dissolved, the melt has a lower viscosity, through which bubbles can move faster and thus help the quartz particles dissolve faster. Also, accumulation of bubbles causes foaming while the melt is gradually homogenized. This dynamical interaction between quartz grains, melt, and bubbles depends on temperature history.

Based on data for the heating rates of 5 and $15 \mathrm{~K} \cdot \mathrm{min}^{-1}$, we are able to only approximate $A$, with the linear function $A / \mathrm{s}^{-1}=2.257+0.475(\beta)$, where $\beta$ is the heating rate $\left(\mathrm{K} \cdot \mathrm{min}^{-1}\right)$. As Fig. 3 shows, average values of $n$ and $B$ together with heating-rate dependent $A$ fit the measured values, and allow interpolation at $10 \mathrm{~K} \cdot \mathrm{min}^{-1}$; the extrapolation to $25 \mathrm{~K} \cdot \mathrm{min}^{-1}$ appears reasonable, but extrapolations to even higher heating rates will have to be verified experimentally.

One of the purposes of simulating quartz dissolution is to assess the fraction of quartz and the size of quartz particles at the interface between the cold cap and the circulating glass melt. The temperature at the interface depends on the intensity of melt circulation. With melt circulating by 
natural convection, the interface temperature can be as low as $950^{\circ} \mathrm{C}$, whereas with forced convection due to bubbling, it can be as high as $1150^{\circ} \mathrm{C}$. Disregarding the change of particle shape during dissolution, the average particle size, $d$, can be approximated as $d=d_{0} x^{1 / 3}$, where $d_{0}$ is the initial size. Fig. 4 displays the fraction and size of undissolved quartz as it exits the cold cap into the molten glass as a function of heating rate for various cold-cap bottom temperatures and the initial size $d_{0}=75 \mu \mathrm{m}$. The estimated size agrees with the sizes of quartz particles seen in Fig. 1, where the cold cap was produced in a laboratory-scale melter with no bubbling; the cold cap bottom temperature was $\sim 1000^{\circ} \mathrm{C}$.

\subsection{Spinel growth and dissolution}

Spinel crystals are solid solutions of magnetite $\left(\mathrm{Fe}_{3} \mathrm{O}_{4}\right)$, trevorite $\left(\mathrm{NiFe}_{2} \mathrm{O}_{4}\right)$, and other simple spinels containing $\mathrm{Cr}, \mathrm{Mn}, \mathrm{Zn}, \mathrm{Ru}$, etc., if these elements are present in the batch. In an ironcontaining melter feed, hematite crystallizes from amorphous $\mathrm{Fe}_{2} \mathrm{O}_{3}$ and turns into spinel by reactions of the type

$$
6 \mathrm{Fe}_{2} \mathrm{O}_{3} \rightarrow 4 \mathrm{Fe}_{3} \mathrm{O}_{4}+\mathrm{O}_{2}
$$

and

$$
\mathrm{Fe}_{2} \mathrm{O}_{3}+\mathrm{NiO} \rightarrow \mathrm{NiFe}_{2} \mathrm{O}_{4}
$$

Fig. 5 displays measured mass fractions of hematite and spinel in batches heated at 5 and $15 \mathrm{~K} \cdot \mathrm{min}^{-1}$. The hematite-to-spinel conversion does not exhibit any discernible dependence on the heating rate. This indicates that the rate of the dominant reaction (R1) is high and close to equilibrium even as the temperature is increasing. Quartz dissolution affects diffusion-controlled spinel-forming reactions, such as (R2), where NiO diffuses to hematite crystals from the melt; with less silica in the melt, diffusion processes advance more rapidly. As a result, the effect of heating rate on spinel generation by both the redox reaction and the diffusion-controlled reaction is insignificant. 
The phase equilibrium line in Fig. 5 represents Eq. (3) fitted to measured spinel fractions in the glass samples heated at a constant temperature for 24 hours (see Section 3). Two parameters, $B_{L}=$ $3152 \mathrm{~K}$ and $T_{L}=1303^{\circ} \mathrm{C}(1576 \mathrm{~K})$, were obtained by least-squares optimization; the third parameter, $c_{\max }=0.047$, was estimated as the sum of the initial trevorite and hematite fractions [4] (see Fig. 5). The $T_{L}$ value was also estimated using mathematical models reported in [35, 36,37]. A model based on XRD data predicted $T_{L}=1305^{\circ} \mathrm{C}$, but close agreement with the measured value is fortuitous: the other three main models listed in [36] estimated $T_{L}$ in the range of $1250-1260^{\circ} \mathrm{C}$.

The phase equilibrium line in Fig. 5 demarcates a subequilibrium area in which spinel crystals grow. Once spinel fraction exceeds the equilibrium line, crystals begin to dissolve. The dashed line in Fig. 5 indicates the spinel fraction as it would evolve in the absence of dissolution. Assuming that spinel originates from hematite, and neglecting interactions of hematite and spinel with the melt, we can write

$$
C_{s}=c_{s i}+p\left(c_{h i}-c_{h}\right)
$$

where $c_{h}$ is the hematite fraction, $p=v M_{s} / M_{h}$ is the hematite-to-spinel ratio, $v$ is the stoichiometric coefficient, and $M$ is the molecular mass; the subscripts $s, h$, and $i$ designate spinel, hematite, and the initial value. Based on reactions (R1) and (R2), $p=0.97$ for magnetite and 1.47 for trevorite. We did not attempt to assess $p$ via an estimate of the magnetite and trevorite fractions in the spinel. However, as Fig. 5 illustrates, Eq. (4) fitted the subequilibrium spinel fraction reasonably well with $p=1$.

The somewhat higher fractions of spinel found in samples heated at $15 \mathrm{~K} \cdot \mathrm{min}^{-1}$ than in those heated at $5 \mathrm{~K} \cdot \mathrm{min}^{-1}$ for temperatures $1100^{\circ} \mathrm{C}$ and $1200^{\circ} \mathrm{C}$ indicate that the rate of spinel dissolution decreased as the heating rate increased. This presumed effect of heating rate on spinel dissolution appears plausible. Above $1000^{\circ} \mathrm{C}$, the batch-to-melt conversion is nearly complete and experimental uncertainty is thus lower than it is at temperatures below $1000^{\circ} \mathrm{C}$, where data fluctuated considerably. The effect of the heating rate on the rate of dissolution is relatively weak, implying that two competing effects are operating: while spinel has less time to dissolve at a higher heating rate, its rate of 
dissolution is accelerated because the fraction of dissolved quartz (see Section 4.1), and thus the melt viscosity, is lower, allowing a faster diffusion. As seen in Figs. 3 and 5, quartz and spinel are dissolving simultaneously. However, as $1150^{\circ} \mathrm{C}$ and $1200^{\circ} \mathrm{C}$ data indicate, the fraction of undissolved quartz is too low to fully offset the direct effect of heating rate.

To mathematically describe the growth and dissolution of spinel, Eqs. (2) and (4) are combined as follows:

$$
\frac{\mathrm{d} c_{s}}{\mathrm{~d} t}=-p \frac{d c_{h}}{d t}+2 k_{H}\left(c_{s 0}-c_{s}\right) \exp \left(-B_{H} / T\right)
$$

We fitted this equation to 5 and $15 \mathrm{~K} \cdot \mathrm{min}^{-1}$ data, ignoring the point at $T=900^{\circ} \mathrm{C}$ of the $15 \mathrm{~K} \cdot \mathrm{min}^{-1}$ run, an obvious outlier. To keep the activation energy independent of heating rate, we enforced a single $B_{H}$ value on the fit, while allowing $k_{H}$ to vary with the heating rate. The least-squares optimization yielded $B_{H}=6381 \mathrm{~K}$, and $k_{H}=0.0467 \mathrm{~s}^{-1}$ and $0.1257 \mathrm{~s}^{-1}$ for $5 \mathrm{~K} \cdot \mathrm{min}^{-1}$ and $15 \mathrm{~K} \cdot \mathrm{min}^{-1}$, respectively. The two 5 and $15 \mathrm{~K} \cdot \mathrm{min}^{-1}$ lines in Fig. 6 illustrate the fits.

The $c_{\text {s. }}$ versus $T$ lines calculated for the 15 and $5 \mathrm{~K} \cdot \mathrm{min}^{-1}$. heating rates within the temperature interval from $900^{\circ} \mathrm{C}$ to $1200^{\circ} \mathrm{C}$ appear close to each other (Fig. 6). However, their distance, defined as the difference $\delta=c_{s}\left(15 \mathrm{~K} \cdot \mathrm{min}^{-1}\right)-c_{s}\left(5 \mathrm{~K} \cdot \mathrm{min}^{-1}\right)$ averaged over this temperature interval, is $\delta=$ 0.0030. It compares favorably with the standard deviation between measured and calculated crystal mass fractions, $\sigma=0.0017$ (the $900^{\circ} \mathrm{C}$ outlier at $15 \mathrm{~K} \cdot \mathrm{min}^{-1}$. was excluded). The ratio $\delta / \sigma=1.7$ indicates $\sim 70 \%$ probability that the assumed effect of the rate of heating on quartz dissolution is real.

\section{Discussion}

For an independent $n^{\text {th }}$-order reaction, one can obtain representative values of the kinetic parameters $A, n$, and $B$ based on data for just one non-isothermal experiment performed at a single constant heating rate. The resulting kinetic model is then applicable for a reasonably wide range of heating rates. In this work we tested the validity of this assumption by conducting the experiment at 
two heating rates. The result clearly showed that the heating rate affected the dissolution kinetics of both quartz and spinel. Hence, the dissolution of quartz particles and spinel crystals in glass are processes in which interactions clearly are manifested. Formation, growth and motion of bubbles influence quartz dissolution [2, 12] and the extent of quartz dissolution affects, in turn, the kinetics of spinel dissolution. The behavior of quartz and spinel is subjected to the time-temperature history of melting.

Interdependent processes preclude the application of standard kinetic formulas with coefficients invariant with respect to the rate of heating. This, by necessity, makes mathematical description of such processes rather complicated. The conflicting needs to describe the behavior of quartz and spinel as realistically as possible while keeping the kinetic equations as simple as possible necessitated compromises. Thus, we have assumed that $n$ and $B$ values for quartz dissolution, and $B_{H}$ for spinel dissolution, are constant, while only the pre-exponential factors, $A$ for quartz and $k_{H}$ for spinel, are functions of heating rates. Treating only one kinetic coefficient, the pre-exponential factor, as a function of the heating rate, while keeping the activation energy constant, was enabled by the relatively narrow range of the experimental heating rate. The heating rates used in this study, 5 and 15 $\mathrm{K} \cdot \mathrm{min}^{-1}$, only partly overlap with the span of heating rate variation experienced in actual cold caps. Both model calculations [22] and experiments [38] show that the heating rate of the batch in the cold cap is expected to be confined to the range of $5-50 \mathrm{~K} \cdot \mathrm{min}^{-1}$. Extrapolation to faster heating should not be performed unless experimentally verified.

\section{Conclusions}

Dissolution of quartz particles, a dominant process in glass making, is affected by the rate of heating both directly and via the formation and removal of gas bubbles. These two effects partially compensate each other. Therefore, it is impossible to represent quartz dissolution by a simple kinetic equation with constant coefficients. Similarly, spinel dissolution in molten glass is subjected to a strong influence of simultaneously occurring processes resulting in changing melt chemistry (mainly silica fraction) and hydrodynamics (associated with bubble motion). The formation of spinel from hematite appears unaffected by the heating rates, at least up to $15 \mathrm{~K} \cdot \mathrm{min}^{-1}$, because this reaction is 
rapid. We were able to represent the dissolution of quartz and spinel with standard kinetic equations in which one coefficient was allowed to change with the rate of heating. This simplification allowed us to keep the kinetic equations in a form suitable for application in mathematical modeling of the batch-toglass conversion as it occurs in glass melters.

\section{Acknowledgments}

This work was supported by the Department of Energy’s Waste Treatment \& Immobilization Plant Federal Project Office under the direction of Dr. Albert A. Kruger and by the WCU (World Class University) program through the National Research Foundation of Korea funded by the Ministry of Education, Science and Technology (R31 - 30005). Richard Pokorny acknowledges financial support from specific university research (MSMT No. 20/2013). The authors are grateful to Jaehun Chun and Dong-Sang Kim for insightful discussions and Derek R. Dixon for providing the scanning electron micrograph image. Pacific Northwest National Laboratory is operated for the U.S. Department of Energy by Battelle under Contract DE-AC05-76RL01830.

\section{References:}

1. M. Cable, in: D.R. Uhlmann, N.J. Kreidl (Eds.), Glass: Science and Technology, Academic Press, 1984.

2. P. Hrma, J. Marcial, K.J. Swearingen, S.H. Henager, M.J. Schweiger, N.E. TeGrotenhuis, J. NonCryst. Solids 357 (2011) 820-828.

3. J. Alton, T.J. Plaisted, P. Hrma, Chem. Eng. Sci. 57 (2002) 2503 - 2509.

4. J. Alton, T.J. Plaisted, P. Hrma, J. Non-Cryst. Solids 311 (2002) 24-35.

5. K. S. Matlack, W.K. Kot, W. Gong, W. Lutze, I.L. Pegg, I. Joseph, Effects of High Spinel and Chromium Oxide Crystal Contents on Simulated HLW Vitrification in DM100 Melter Tests, Department of Energy Office of River Protection, VSL-09R1520-1 (2009).

6. P. Hrma, J. Non-Cryst. Solids, 356 (2010) 3019-3025.

7. M. Jiricka, L. Nemec, Ceram. Silik. 46(4) (2002) 127-132. 
8. J. Matyas, J.D. Vienna, A. Kimura, M.J. Schaible, R.M. Tate, Chapter 5 in: K. Fox, E. Hoffman, N. Manjooran, G. Pickrell (Eds.), Development of Crystal-Tolerant Waste Glasses, Advances in Materials Science for Environmental and Nuclear Technology: Ceramic Transactions, 222, John Wiley \& Sons, Inc., Hoboken, NJ, 2010, pp. 41-51

9. J.S. McCloy, M.J. Schweiger, C.P. Rodriguez, J.D. Vienna, Int. J. Appl. Glass Sci. 3 (2011) 20114.

10. H. Li, P. Hrma, J.D. Vienna, M. Qian, Y. Su, D.E. Smith, J. Non-Cryst. Solids, 331 (2003) 202216.

11. M.J. Schweiger, P. Hrma, C.J. Humrickhouse, J. Marcial, B.J. Riley, N.E. TeGrotenhuis, J. NonCryst. Solids 356 (2010) 1359-1367.

12. P. Hrma, J. Marcial, J. Non-Cryst. Solids 357 (2011) 2954-2959.

13. P. Hrma, J. Alton, J. Klouzek, J. Matyas, M. Mika, L. Nemec, T.J. Plaisted, P. Schill, M. Trochta, Increasing High-Level Waste Loading in Glass without Changing the Baseline Melter Technology, Waste Management '01, University of Arizona, Tucson, Arizona, 2001.

14. D.G. Casler, P. Hrma, Mat. Res. Soc. Proc. 556 (1999) 255-262.

15. P. Hrma, J. Alton, Dissolution and Growth of Spinel Crystals in a High-Level Waste Glass, Proceedings of the $8^{\text {th }}$. International Conference on Radioactive Waste Management and Environmental Remediation (ICEM’01), CD-ROM, Bruges, Belgium.

16. P. Izak, P. Hrma, B.W. Arey, T.J. Plaisted, J. Non-Cryst. Solids 289 (2001) 17-29.

17. P. Hrma, P. Izak, J.D. Vienna, M.-L. Thomas, G.M. Irwin, Phys. Chem. Glasses (UK), 43(2) (2002) 119-127.

18. S. Annamalai, H. Gan, M. Chaudhuri, W.K. Kot, I.L. Pegg, Ceram Trans. 155 (2004) 279-288.

19. P. Schill, M. Trochta, J. Matyas, L. Nemec, P. Hrma, Mathematical model of spinel settling in a real waste glass melter, Waste Management '01, University of Arizona, Tucson, Arizona, 2001.

20. P. Hrma, J. Matyáš, D.-S. Kim. The Chemistry and Physics of Melter Cold Cap, $9^{\text {th }}$ Biennial Int. Conf. On Nucl. and Hazardous Waste Management, Spectrum '02, American Nuclear Society, CD-ROM, 2002. 
21. J. Matyáš, J. Kloužek, L. Němec, M. Trochta, Spinel Settling in HLW Melters, ICEM’01 The $8^{\text {th }}$. International Conference on Environmental Management, Bruges, Belgium, 2001.

22. R. Pokorny, P. Hrma, J. Nucl. Mater. 429 (2012) 245-256.

23. R.A. Kirkbridge, G.K. Allen, R.M. Orme, R.S. Wittman, J.H. Baldwin, T.W. Crawford, J.Jo, L.J. Fergestrom, T.M. Hohl, D.L. Penwell, Tank Waste Remediation System Operation and Utilization Plan to Support Waste Feed Delivery, Vol. I, HNF-SD-WM-SP-012, Numatec Hanford Corporation, Lockheed Martin Hanford Corporation, and Cogema Engineering, Richland,Washington (1999).

24. K.S. Matlack, H. Gan, M. Chaudhuri, W.K. Kot, W.Gong, T. Bardakci, I. Joseph, I.L. Pegg, Melt Rate Enhancement for High Aluminum HLW Glass Formulations, VSL-08R1360-1, Rev. 0, Vitreous State Laboratory of The Catholic University of America, Washington, DC, 2008.

25. R. Pokorny, D. A Pierce, P. Hrma, Thermochim. Acta 541 (2012) 8-14.

26. J. Chun, D.A. Pierce, R. Pokorny, P. Hrma, Thermochim. Acta 559 (2013) 32-39.

27. A.W. Hixson, J.H. Crowell, Ind. Eng. Chem. 23 (1931) 923-931.

28. V.G. Levich, Physicochemical Hydrodynamics, Prentice-Hall, Englewood Cliffs, NY, 1962, p. 80.

29. M. Jiricka, P. Hrma, J.D. Vienna, J. Non-Cryst. Solids 319 (2003) 280-288.

30. P. Hrma, J. Non-Cryst. Solids 356 (2010) 3019-3025.

31. K.S. Matlack, W.K. Kot, W.Gong, I.L. Pegg, Small scale melter testing of HLW algorithm glasses: matrix 1 tests, VSL-07R1220-1, Vitreous State Laboratory of The Catholic University of America, 2007.

32. S.H. Henager, P. Hrma, K.J. Swearingen, M.J. Schweiger, J. Marcial and N.E. TeGrotenhuis, J. Non-Cryst. Solids 357 (2011) 829-835.

33. D.A. Pierce, P. Hrma, J. Marcial, B.J. Riley, M.J. Schweiger, Int. J. Appl. Glass Sci. 3 (2012) 5968.

34. R. Pokorny, J.A. Rice, M.J. Schweiger, P. Hrma, J. Am. Ceram. Soc., accepted (2013).

35. M.J. Schweiger, B.J. Riley, J.V. Crum, P. Hrma, C.P. Rodriguez, B.M. Arrigoni, J.B. Lang, D.S. Kim, J.D. Vienna, F.C. Raszewski, D.K. Peeler, T.B. Edwards, D.R. Best, I.A. Reamer, W.T. Riley, P.T. Simmons, R.J. Workman, Expanded High-Level Waste Glass Property Data 
Development: Phase I, PNNL-17950, Pacific Northwest National Laboratory, Richland, WA, USA, 2011.

36. P. Hrma, B.J. Riley, J.V. Crum, J. Matyas, J. Non-Cryst. Solids (2013), In Press, http://dx.doi.org/10.1016/j.jnoncrysol.2013.02.014.

37. M. Mika, M.J. Schweiger, J.D. Vienna, P. Hrma, in Proc. Sci. Basis Nucl. Waste Manag. XX, 465 (1997) 71-78.

38. D.R. Dixon, M.J. Schweiger, P. Hrma, Effect of Feeding Rate on the Cold Cap Configuration in a Laboratory-Scale Melter, Proceedings of the 39th Annual Waste Management Conference, WM2013, February 24-28, 2013, Phoenix, Arizona USA, ISBN 978-0-9836186-2-1. 
Figure captions

Fig. 1 Scanning electron micrograph showing quartz residues (dark gray) and spinel crystals (white) in glass under the cold cap.

Fig. 2 Undissolved fraction of quartz in batch versus temperature for two heating rates. The dashed lines represent a hyperbolic tangent function fitted to data at $T>700^{\circ} \mathrm{C}$ and solid lines represent the $n^{\text {th }}$-order kinetic model, Eq. (1), with parameters listed in Table 2.

Fig. 3 Quartz dissolution kinetics with average values of $n$ and $B$ and heating-rate dependent $A$. Solid points represent the measured values.

Fig. 4 Fraction (left) and particle size (right) of undissolved silica exiting the cold cap as a function of heating rate and cold cap bottom temperature (shown in the legend in ${ }^{\circ} \mathrm{C}$ ).

Fig. 5 Spinel and hematite fractions as they evolved during batch-to-glass conversion at heating rates 5 and $15 \mathrm{~K} \cdot \mathrm{min}^{-1}$. Solid triangles on the equilibrium line represent fractions of spinel in phase equilibrium with homogeneous glass; data were fitted with Eq. (3). Hematite fraction (thicker solid line) was fitted with a hyperbolic tangent and the subequilibrium fraction (dotted line) of spinel was fitted with Eq. (4). In its extension to higher temperatures (above the equilibrium line), the dotted line indicates how the spinel fraction would evolve in the absence of dissolution.

Fig. 6 Spinel fraction evolution during batch-to-glass conversion at 5 and $15 \mathrm{~K} \cdot \mathrm{min}^{-1}$. The lines for hematite fraction and spinel equilibrium are the same as in Fig. 5. 
Table 1. Melter feed composition (in g) to make $1 \mathrm{~kg}$ of glass

\begin{tabular}{|c|c|}
\hline Compound & $\mathrm{g} \cdot \mathrm{kg}^{-1}$ \\
\hline $\mathrm{Al}(\mathrm{OH})_{3}$ & 367.49 \\
\hline $\mathrm{H}_{3} \mathrm{BO}_{3}$ & 269.83 \\
\hline $\mathrm{CaO}$ & 60.79 \\
\hline $\mathrm{Fe}(\mathrm{OH})_{3}$ & 73.82 \\
\hline $\mathrm{Li}_{2} \mathrm{CO}_{3}$ & 88.30 \\
\hline $\mathrm{Mg}(\mathrm{OH})_{2}$ & 1.69 \\
\hline $\mathrm{NaOH}$ & 99.41 \\
\hline $\mathrm{SiO}_{2}$ & 305.05 \\
\hline $\mathrm{Zn}\left(\mathrm{NO}_{3}\right)_{2} \cdot 4 \mathrm{H}_{2} \mathrm{O}$ & 2.67 \\
\hline $\mathrm{Zr}(\mathrm{OH})_{4} \cdot 0.65 \mathrm{H}_{2} \mathrm{O}$ & 5.49 \\
\hline $\mathrm{Na}_{2} \mathrm{SO}_{4}$ & 3.55 \\
\hline $\mathrm{Bi}(\mathrm{OH})_{3}$ & 12.80 \\
\hline $\mathrm{Na}_{2} \mathrm{CrO}_{4}$ & 11.13 \\
\hline $\mathrm{KNO}_{3}$ & 3.04 \\
\hline $\mathrm{NiCO}_{3}$ & 6.36 \\
\hline $\mathrm{Pb}\left(\mathrm{NO}_{3}\right)_{2}$ & 6.08 \\
\hline $\mathrm{Fe}\left(\mathrm{H}_{2} \mathrm{PO}_{2}\right)_{3}$ & 12.42 \\
\hline $\mathrm{NaF}$ & 14.78 \\
\hline $\mathrm{NaNO}_{2}$ & 3.37 \\
\hline $\mathrm{Na}_{2} \mathrm{C}_{2} \mathrm{O}_{4}$ & 1.26 \\
\hline Total & 1349.32 \\
\hline
\end{tabular}


Table 2. Quartz dissolution kinetic parameters, Eq. (1), as functions of heating rate $(\beta)$

\begin{tabular}{lcc}
$\beta\left(\mathrm{K} \cdot \mathrm{min}^{-1}\right)$ & 5 & 15 \\
\hline$A\left(\mathrm{~s}^{-1}\right)$ & 2.33 & 18.1 \\
$n$ & 1.33 & 1.38 \\
$B(\mathrm{~K})$ & 8763 & 10166
\end{tabular}




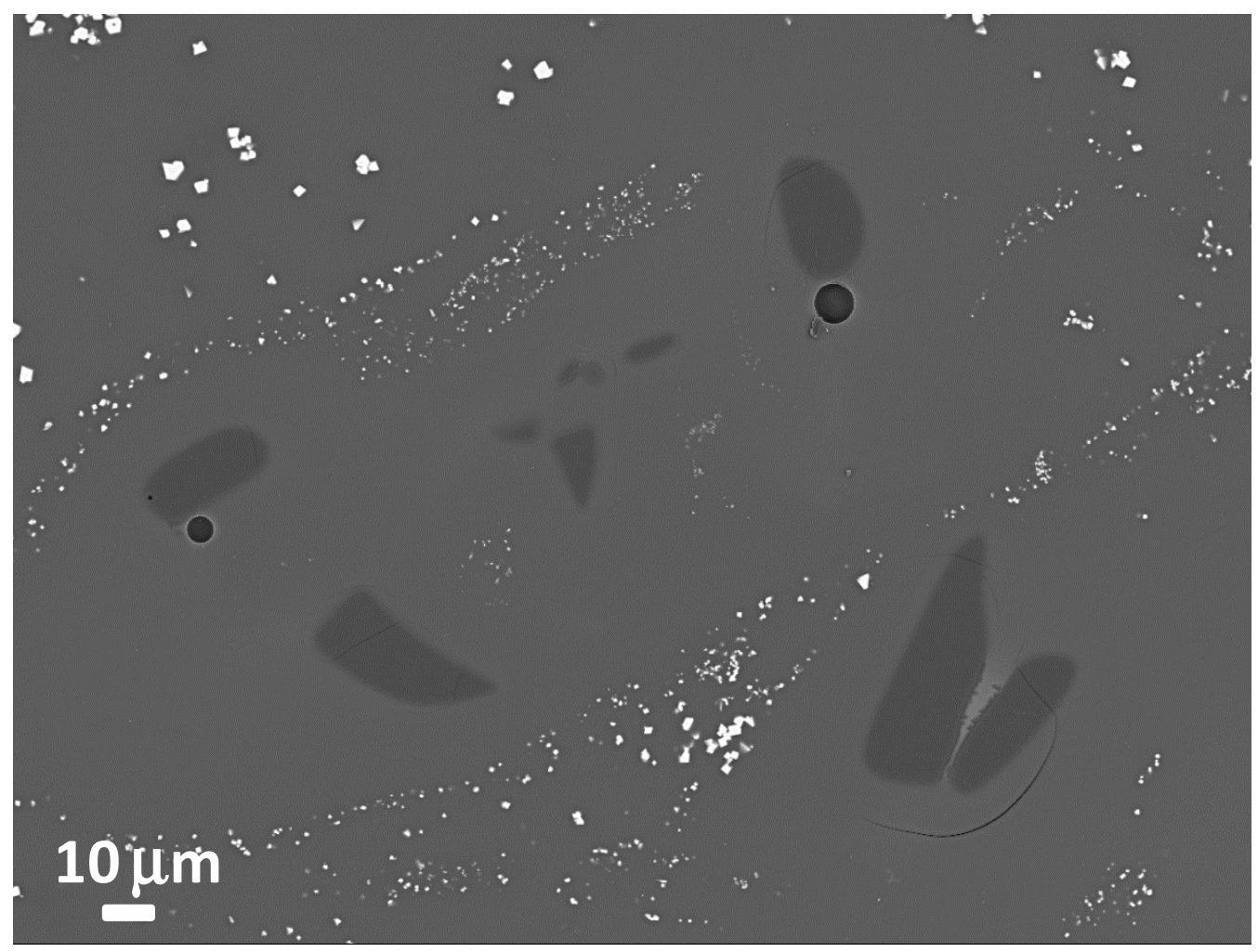

Fig. 1 Scanning electron micrograph showing quartz residues (dark gray) and spinel crystals (white) in glass under the cold cap. 


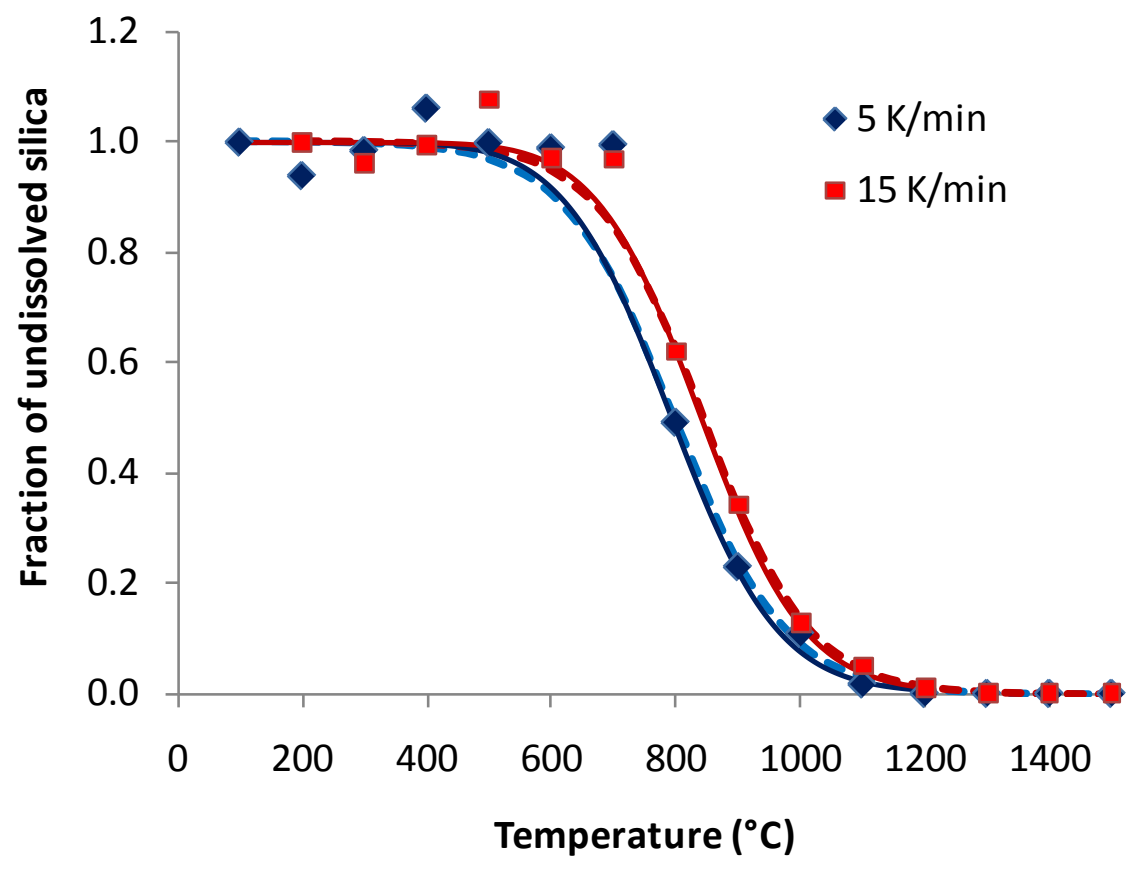

Fig. 2 Undissolved fraction of quartz in batch versus temperature for two heating rates. The dashed lines represent a hyperbolic tangent function fitted to data at $T>700^{\circ} \mathrm{C}$ and solid lines represent the $n^{\text {th }}$-order kinetic model, Eq. (1), with parameters listed in Table 2. 


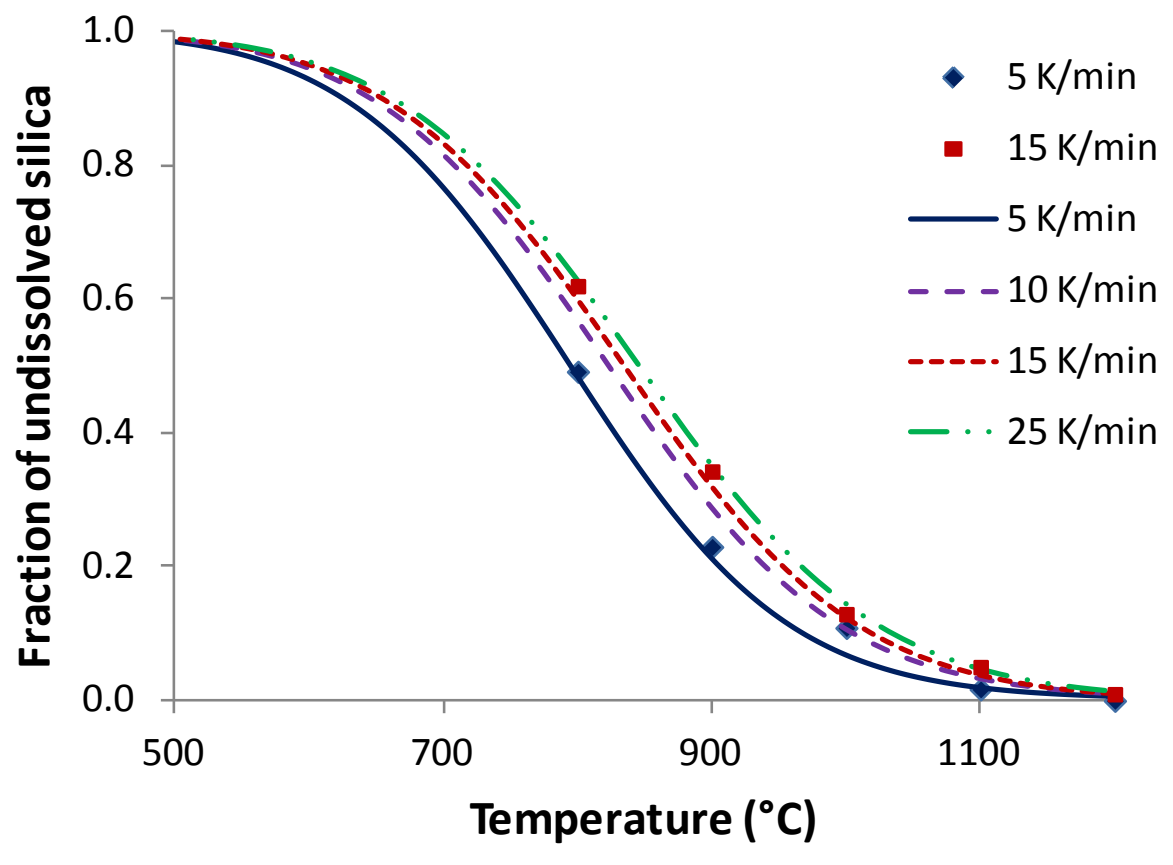

Fig. 3 Quartz dissolution kinetics with average values of $n$ and $B$ and heating-rate dependent $A$. Solid points represent the measured values. 

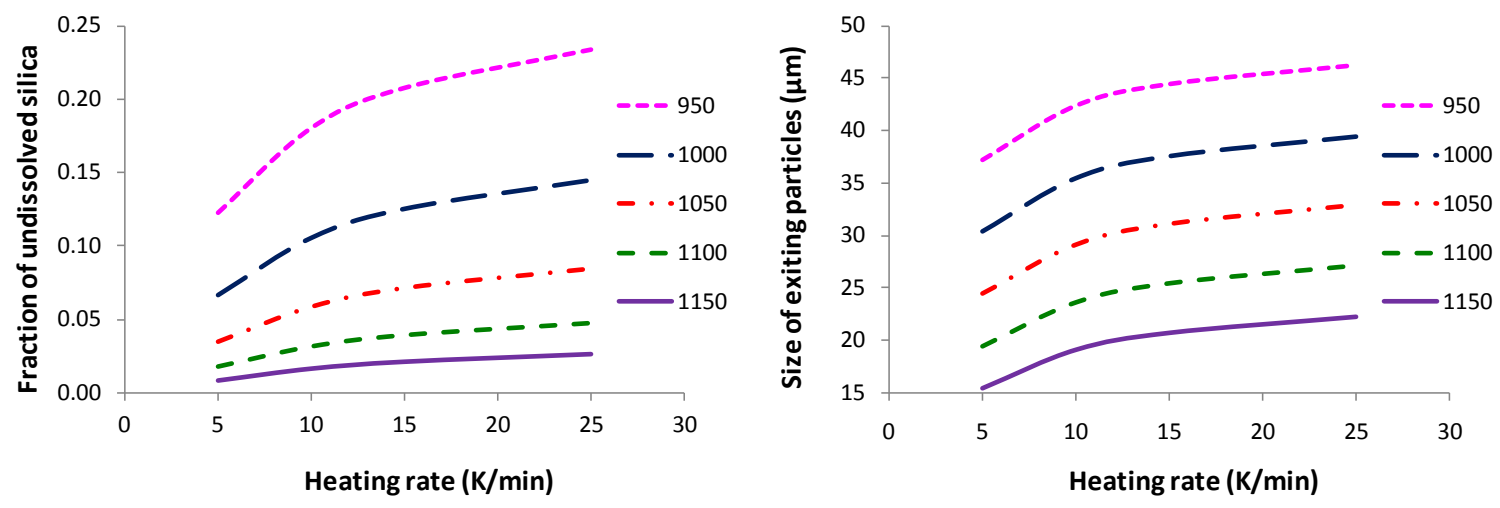

Fig. 4 Fraction (left) and particle size (right) of undissolved silica exiting the cold cap as a function of heating rate and cold cap bottom temperature (shown in the legend in ${ }^{\circ} \mathrm{C}$ ). 


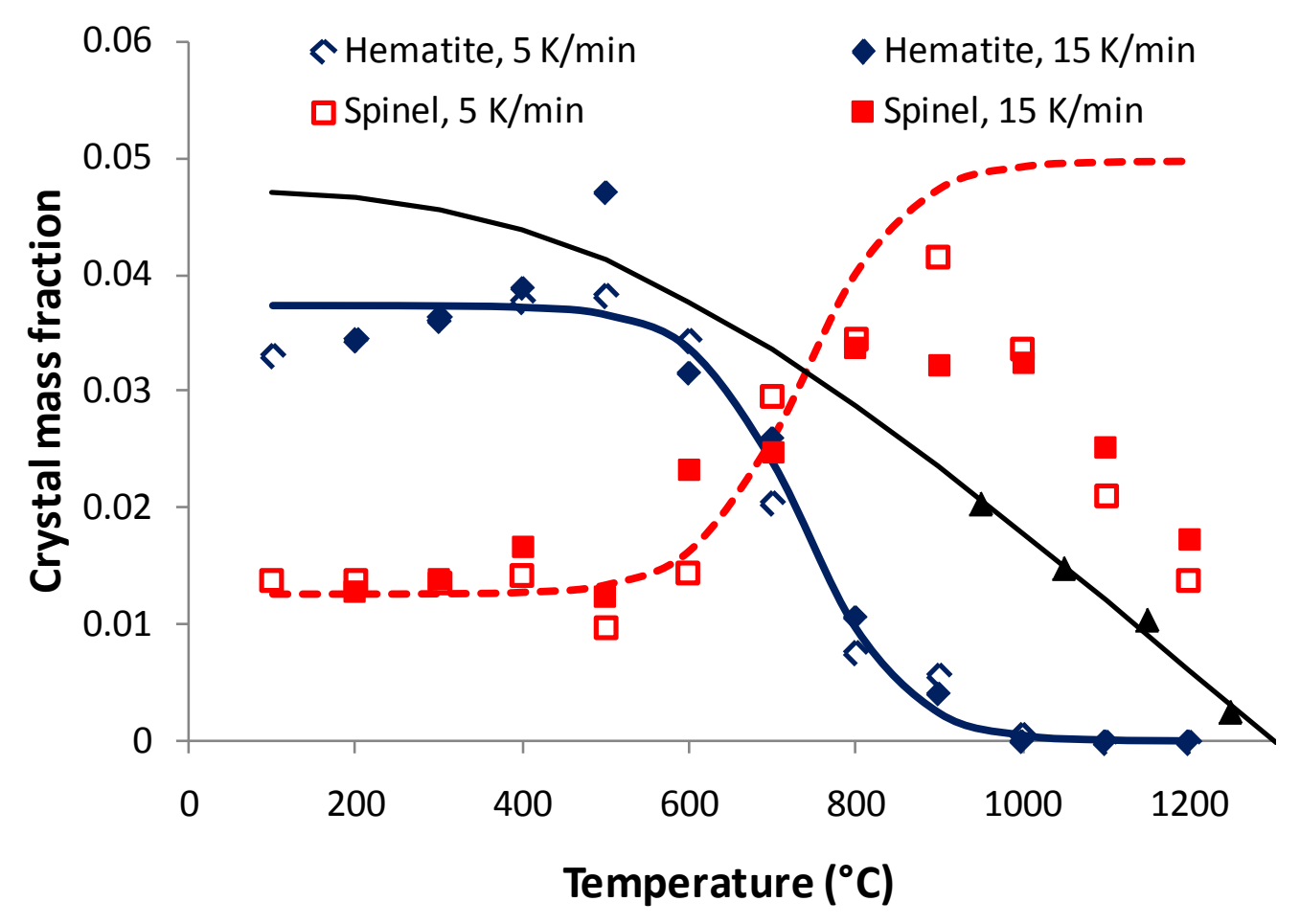

Fig. 5 Spinel and hematite fractions as they evolved during batch-to-glass conversion at heating rates 5 and $15 \mathrm{~K} \cdot \mathrm{min}^{-1}$. Solid triangles on the equilibrium line represent fractions of spinel in phase equilibrium with homogeneous glass; data were fitted with Eq. (3). Hematite fraction (thicker solid line) was fitted with a hyperbolic tangent and the subequilibrium fraction (dotted line) of spinel was fitted with Eq. (4). In its extension to higher temperatures (above the equilibrium line), the dotted line indicates how the spinel fraction would evolve in the absence of dissolution. 


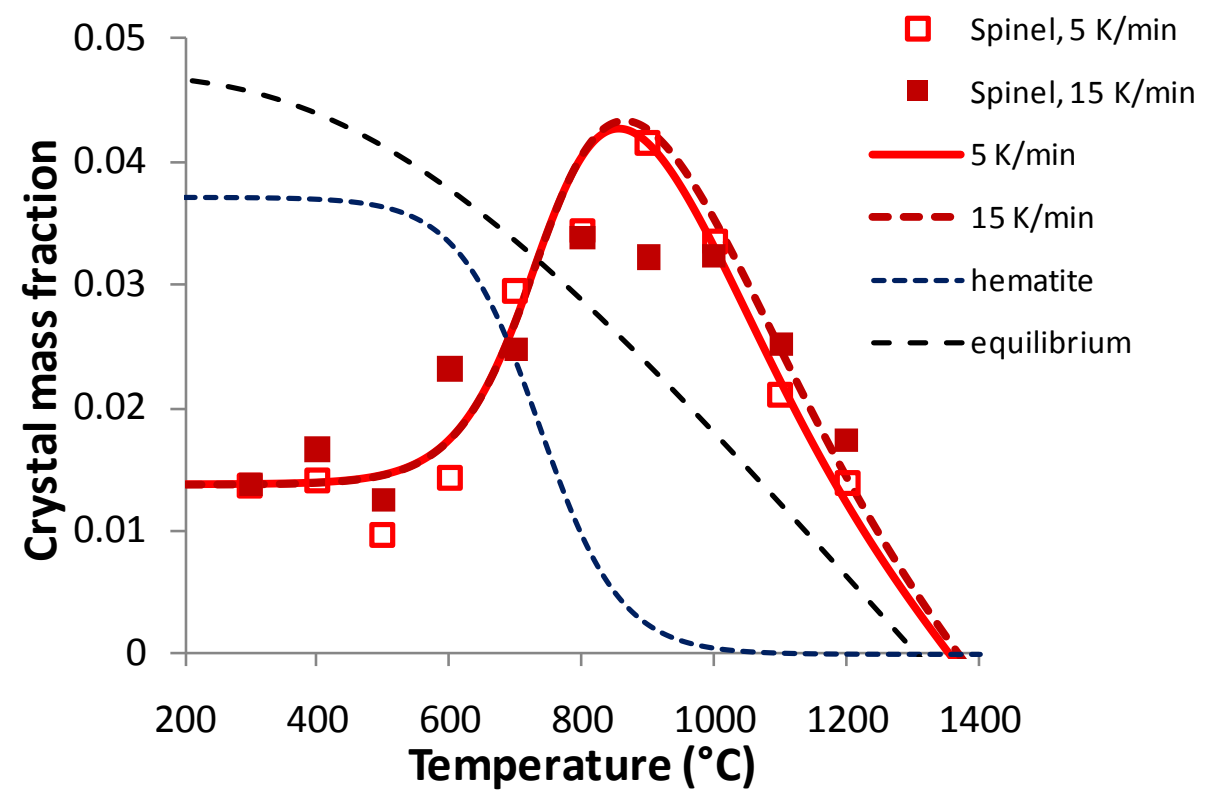

Fig. 6 Spinel fraction evolution during batch-to-glass conversion at 5 and $15 \mathrm{~K} \cdot \mathrm{min}^{-1}$. The lines for hematite fraction and spinel equilibrium are the same as in Fig. 5. 